\title{
Climate Change and Soil Hydrology: European Perspectives
}

\author{
Satish Bastola, Suresh Kumar, Conor Murphy \\ and John Sweeney*
}

\section{Introduction}

The climate of Europe has been changing along similar lines to that of the globe as a whole, with warming of $0.9^{\circ} \mathrm{C}$ being experienced over the period 1901-2005 (Alcamo et al., 2007). Though future changes in rainfall to be expected as a result of continued warming are subject to large uncertainties, mean rainfall intensity is expected to increase significantly across the continent, irrespective of local changes in annual or seasonal receipt (Giorgi et al., 2004). Of more significance for soil processes and soil hydrology is the substantially increased likelihood of extreme precipitation events.

Soils represent a short- to long-term carbon storage medium. Increased temperatures can be expected to accelerate biological decomposition activity in the upper horizons and this will decrease carbon storage. These changes in soil organic matter also have implications for soil moisture storage, and changes in soil moisture driven by future changes in climate are likely to have significant implications for the structure and dynamic of ecosystems, agricultural production and water availability (Frederick and Major, 1997). Therefore, soils, and consequently soil hydrology, are likely to be highly sensitive to climate change. Soil hydrological processes determine how precipitation is partitioned into infiltration, runoff, evapotranspiration and groundwater recharge. Consequently, both surface water resources and the soil moisture store react to the changes in temperature and precipitation.

Precipitation and runoff are direct driving forces of soil erosion and sediment transport. Variation of precipitation will most likely lead to changes in surface runoff, soil erosion and sediment dynamics. In addition to the direct effect on soil arising from higher temperature and greater variability in rainfall, the effect from climate-induced increases or decreases of vegetative cover, alteration in land-use practices and water-use efficiency can also have a significant impact on soil. Increasing air temperatures also affect soil erosion indirectly by changing: (i) growing days for crop maturity, (ii) microbial activity levels, and (iii) crop management practices. Favis-Mortlock and Boardman (1995) suggest that a 7\% increase in precipitation could lead to a $26 \%$ increase in erosion in the UK. Similarly, Pruski and Nearing (2002) show, using the HadCM3 (Hadley Centre Global Climate Model from the UK Met Office Hadley Centre for Climate Prediction and Research) prediction coupled with the Water Erosion Prediction Project-Carbon Dioxide

\footnotetext{
* Corresponding author: John.Sweeney@ nuim.ie
} 
(WEPP-CO2) model for eight locations in the USA, that erosion increased substantially where precipitation was predicted to increase significantly. Erosion rates are also sensitive to land use and existing conservation practices at the field or farm level. Soil erosion has been identified as the most severe hazard threatening the protection of soil in Europe. Kosmas et al. (1997) studied the effect of land use and precipitation on annual runoff and sediment loss at eight different sites along the northern Mediterranean region and the Atlantic coastline located in Portugal, Spain, France, Italy and Greece. They found that land use can greatly affect runoff and soil erosion in this region. Several studies have been conducted on the effects of climate change on soil erosion using computer simulation models such as the Universal Soil Loss Equation (USLE), SWAT (Soil and Water Assessment Tool) (Neitsch et al., 2002), WEPP (Water Erosion Prediction Project) (Flanagan and Livingston, 1995), EUROSEM (European Soil Erosion Model) (Morgan et al., 1998), KINEROS2 (Kinematic Runoff and Erosion Model) (Smith et al., 1995) and LISEM (Limburg Soil Erosion Model) (De Roo et al., 1996). These models have the potential to respond explicitly and rationally to changes in climate or land use, and have a potential for developing scenarios of change, thus helping in the assessment of policy or economic options.

Improved understanding of how climate change could influence soil hydrology has also been an important research topic. Hydrological simulation models are often used together with climate scenarios generated from Global Climate Models (GCMs) to evaluate the impacts of potential climate change on water resources and soil hydrological process. This approach is subject to a range of uncertainties associated with future emissions of greenhouse gases, the response of the climate system to these changes at global and local scales, and uncertainties associated with the impact models themselves. These uncertainties then cascade through the climate change impact assessment methodology, resulting in potentially large uncertainties being associated with critical future impacts at the local scale where key decisions are required in order to increase the resilience of water supply management and infrastructure to future changes. In an attempt to quantify major sources of uncertainties associated with climate change impact assessment, New and Hulme (2000) presented an approach to quantifying the uncertainties associated with the estimation of future greenhouse gas emissions, the climate sensitivity, and limitations and unpredictability in GCMs. Most early studies utilized a single hydrological model and ignored the modelling uncertainties associated with the structure of such models. Because hydrological models are inherently imperfect because they abstract and simplify real patterns and processes that are themselves imperfectly known and understood, and experiences with the calibration of hydrological models suggest that their parameters are inherently uncertain, it is essential to address them in the context of climate change assessments.

Although climate change will certainly affect soil hydrology, impacts will not be distributed uniformly over the globe. Therefore, this chapter aims at reviewing recent research developments in climate change and its consequence for soils, soil moisture and soil erosion from a European perspective and, additionally, aims at highlighting the importance of uncertainty characterization in the response of models at the river basin scale through a case study of Irish catchments.

\section{Materials and Methods}

A Pan-European Soil Erosion Risk Assessment model (PESERA) has been employed to model soil erosion in a changing climate at a European scale (Kirkby et al., 2004). PESERA is a physically based and spatially distributed model developed for quantifying soil erosion in environmentally sensitive areas at a regional or European scale, and to assist with defining soil conservation strategies. It estimates erosion rates in individual storms using a sediment transport equation that has explicit terms for topography, overland flow and soil erodibility. Other soil characteristics and soil/ land cover are implicitly incorporated as a soil runoff threshold. The model's robustness and flexibility has been demonstrated through 
its performance at different resolutions and across different agro-ecological zones. In order to simplify the spatial scale, two subregions of Europe, namely the northern region and the Mediterranean region were used to provide an insight into future erosion risks.

Hydrological simulation models are used together with climate change scenarios generated from GCMs to evaluate the impacts of potential climate change on water resources and soil hydrological processes. This approach is subject to a range of uncertainties. Therefore, to account for different sources of uncertainties in the hydrological impacts of climate change, a multi-model approach that combines multiple emission scenarios, multiple GCMs and multiple conceptual rainfall runoff models was implemented through the application of the methodology to selected Irish catchments. The six available regional climate scenarios derived from three GCM and two SRES (Special Report on Emissions Scenarios, prepared by the Intergovernmental Panel on Climate Change (IPCC) for the Third Assessment Report (TAR) in 2001) greenhouse gas emissions scenarios, namely A2 and B2, and downscaled for Ireland by Fealy and Sweeney (2007), were used to characterize future climate evolutions. The GCMs considered included: HadCM3; CGCM2, from the Canadian Centre for Climate Modelling and Analysis (CCCMA, Canada) and CSIRO-Mk2 from the Commonwealth Science and Industrial Research Organisation (CSIRO, Australia). The A2 and B2 scenarios represent future emissions levels that could be considered 'mediumhigh' (A2 emission) and 'medium-low' (B2 emission). From among the large number of models that can be used for the purpose of modelling flow in catchments, four rainfall runoff models were selected: HyMOD (a conceptual hydrological model; see Wagener et al., 2001, for details), NAM (Nedbor-Afstromnings-Model precipitation-runoff model; see Madsen, 2000, for detailed information), Tank (Sugawara, 1995) and TOPMODEL(Beven et al., 1995). Each of these models varies in the way they conceptualize the key hydrological processes and in complexity, primarily related to the number of parameters requiring calibration. Among the four selected models, NAM and Tank describe the behaviour of each component of the hydro- logical cycle at the catchment level by using a group of conceptual elements. Conversely, TOPMODEL and HyMOD are both variable contributing area models. In TOPMODEL, the spatial variability is taken into account through indices derived from topography, whereas, in HyMOD, the model spatial variability within basin is modelled using a probability distribution function. All four models employ a single linear reservoir to model groundwater. The impact of climate change on water resources at the catchment scale is investigated using four Irish catchments: the River Blackwater at Ballyduff $\left(2302 \mathrm{~km}^{2}\right)$, the River Suck at Bellagill $\left(1219 \mathrm{~km}^{2}\right)$, the River Moy at Rahans $\left(1803 \mathrm{~km}^{2}\right)$ and the River Boyne at Slane $\left(2452 \mathrm{~km}^{2}\right)$. These four catchments were selected to represent the diverse hydrological responses of different catchments located throughout the Republic of Ireland.

\section{Results and Discussion}

\section{Climate change scenarios for Europe}

As already stated, the climate of Europe has been changing along similar lines to that of the globe as a whole. Unlike North America, Europe is exposed much more to the ingress of maritime air masses and its climate trends are therefore strongly influenced by sea surface temperature (SST) trends in the North Atlantic. Ting et al. (2009) have attributed recent trends in Atlantic SSTs to a combination of anthropogenic and natural influences which sometimes combine to amplify or mitigate climate trends in the region. A pronounced warming in SSTs and also in air temperatures has occurred especially since the 1990s, which were the warmest decade in the long instrumental records available from Europe. Not surprisingly, given the dominant maritime influence, European winters have tended to warm to a greater extent than summers. Precipitation changes have shown a marked geographical variation with an increase of $10-40 \%$ being observed in northern Europe and a decrease of up to $20 \%$ being observed in the southern parts of the continent (Alcamo et al., 2007). Indications that mean rainfall intensity is 
increasing are also widely apparent across the continent (Alexander et al., 2006).

A continuation of many of these trends is projected from contemporary modelling exercises. Warming is expected to be greatest in winter in the northern and eastern parts of Europe, while more continental parts are expected to show greatest warming during the summer. A major temperature increase of the order of $6{ }^{\circ} \mathrm{C}$ in summer temperatures is projected for the Iberian Peninsula and southern France (Good et al., 2006). Indeed, the intensity and frequency of summer heatwaves are likely to increase across the continent; one such major event occurring in 2003 has been linked to over 35,000 excess deaths (Johnson et al., 2005). Models also project a continuation of recent trends in precipitation, with mean annual precipitation projected to increase in the north and decrease in the south (Alcamo et al., 2007). In winter, this is driven by increased cyclonic activity as more vigorous depressions from a warmer Atlantic bring maritime conditions further north and east than at present. In summer, the blocking effect of the extension of the Azores anticyclone deflects disturbances towards the Barents Sea, producing a widespread reduction in precipitation. Projections of wind speed changes are less confident and often highly influenced by the choice of models used (Räisänen et al., 2004).

Mean rainfall intensity is expected to increase significantly across the continent, irrespective of local changes in annual or seasonal receipt (Giorgi et al., 2004). Of more significance for soil processes and soil hydrology is the substantially increased likelihood of extreme precipitation events. Though these are most likely to occur in winter, enhanced convective activity during summer is also likely to produce short-duration high-intensity downpours with a substantially increased frequency. Increased summer heatwaves and drought frequency will also have important ramifications for soil processes as the century proceeds.

\section{Climate change and soils}

The sensitivity of soil hydrology to temperature is not straightforward. Kirschbaum (1995) suggested that a $1{ }^{\circ} \mathrm{C}$ increase in temperature could ultimately lead to a loss of over $10 \%$ of soil organic carbon in middle-to-high latitude locations, whereas the same temperature increase would lead to a loss of only $3 \%$ of soil organic carbon in the tropics. Much of northern Europe falls into the former category, suggesting that the north European soil organic carbon reservoir, particularly in peatland soils, may decrease significantly with global warming.

Changes in soil organic matter also have implications for soil moisture storage because soil organic matter can absorb up to 20 times its weight in water. However, an increased incidence of hot and dry summers and mild and wet winters will also have implications for soil moisture and erosion vulnerability. As well as being a major influence on soil processes, soil moisture is an important regulator of surface water flows. Fine-textured soils such as clays and peats can retain large volumes of water and can contribute to increased flood risk in high precipitation events if they are already close to field capacity. Projected increases both in precipitation intensity and in winter rainfall for upland areas of northern and north-western Europe relate to many areas with blanket bog, or to other wet soils such as gleys or peaty podzols derived from glacial deposits. These soils with poor infiltration thus render areas at lower levels more vulnerable to increased flooding. In contrast, coarser soils, derived from fluvioglacial deposits, especially in central and eastern Europe, facilitate infiltration and groundwater recharge better and can therefore mitigate the impact of both flood and drought events.

A further consideration of the relationship between climate change and soil centres on the fact that approximately half of Europe's soil carbon stocks of about $75 \mathrm{Gt}$ are located in Scandinavia, the UK and Ireland, with the single biggest contributor to the total being peatlands. When such soils are drained, they release 20-40 $\mathrm{t}$ of $\mathrm{CO}_{2}$ per annum per hectare. The first priority, therefore, in terms of using soils to combat climate change is to preserve as much as possible of existing peatlands and organic soils. The susceptibility of such soils to drying out and, in the case of peatlands, to cracking and disintegrating, poses a risk that such areas in Europe may become 
carbon sources rather than sinks as warming proceeds. In the case of the Irish peatlands, uncertainty exists as to whether disturbance has already rendered them sources rather than sinks (Ward et al., 2007). Grassland and forest soils are also probably delivering net sequestration of carbon, with cultivated soils performing a similar role to a lesser extent. Land use and land-use change adversely affect soil carbon stocks, particularly when conversion to arable uses occurs.

\section{Soil moisture in a changing climate}

Changes in soil moisture driven by future changes in climate are likely to have significant implications for the structure and dynamics of ecosystems, agricultural production and water availability. In relation to ecosystem functioning and agriculture, a large number of studies have demonstrated the importance of soil moisture deficits as a key indicator of stress for vegetation and shown that a detailed knowledge of climate-induced changes in soil moisture patterns is critical in understanding the magnitude and spatial distribution of future changes in vegetation and crop yield (e.g. Porporato et al., 2001). In terms of water resources, soil moisture is a key component of the hydrological cycle, controlling the partitioning of rainfall between runoff, evapotranspiration and deep infiltration (Daly and Porporato, 2005), thereby determining the water yield of a catchment. Various feedbacks exist between soil moisture and the biological and hydrological cycles. For example vegetation can influence the soil water regime by offsetting drier conditions through decreased transpiration (Etchevers et al., 2002; Seneviratne et al., 2002).

In contrast, dry soils can also cause a negative feedback by amplifying the impact and duration of heatwaves and prolonging the effects of drought (Nicholson, 2000). Brabson et al. (2005) using output from the HadCM3 global climate model showed that longer spells of extreme temperature are seen to arise both from the statistical increase in the frequency of extremes and from the extended periods of low soil moisture. Additionally, Fischer et al. (2007) showed that a lack of soil moisture during the record-breaking European heatwave of summer 2003 was considerably amplified by reductions in soil moisture beginning in spring. The authors highlighted that a lack of soil moisture strongly reduced latent heat cooling, thereby amplifying surface temperature anomalies. Simulations conducted by Fischer et al. (2007) indicated that, without negative soil moisture anomalies, the summer heat anomalies could have been reduced by around $40 \%$ in some regions.

It is obvious then that there is a need to understand how soil moisture is likely to respond to climate change. In meeting this need, the dominant approach to assessing climate change impacts is to use the output from global climate models to assess future changes in soil moisture content. This has not been an easy task to date, and future projections of soil moisture have been considered only by a few studies, not least because of a lack of observations, large ranges in the natural variability of soil moisture conditions and the complexity involved in assessing the temporal and spatial impacts for this variable. Jasper et al. (2006) highlighted that the impact of climate change on soil moisture depends on the interplay of highly complex and nonlinear processes such as infiltration, drainage, capillary rise, evapotranspiration and lateral subsurface flows, with each of these processes being influenced by local area characteristics such as soil type and texture, vegetation characteristics and slope. Therefore, even with a uniform change in temperature and precipitation, changes in soil moisture due to climate change are likely to show a high degree of spatial variability and significant levels of uncertainty.

Of the limited number of studies that have been conducted, the general findings to date indicate a likely increase in the moisture content of soils in winter and a substantial decrease in summer, particularly in southern Europe. In global-scale studies, a number of authors have used output from GCMs directly to simulate changes in soil moisture. Gerten et al. (2007) explored the effects of atmospheric $\mathrm{CO}_{2}$ enrichment and climate change on soil moisture using a dynamic global vegetation and water balance model forced by five different scenarios of change in temperature, precipitation, radiation and atmospheric 
$\mathrm{CO}_{2}$ concentrations. Outputs from this largescale assessment projected a decline in soil moisture for many regions for the period 2071-2100 compared with 1961-1990, with ecosystems in northern temperate latitudes at greatest risk. At the European scale, Gregory et al. (1997) reported that soil moisture in summer is likely to decrease by $10-30 \%$ in southern Europe, driven predominantly by reductions in precipitation and changes in evaporative demands. Following a process investigation, these authors suggested that drying of the soil during summertime is derived from an increase in evaporation in winter and spring due to higher temperatures and reduced snow cover, and a decrease in the net input of rainfall in summer. Reductions in soil moisture are suggested to be sufficiently large to produce a limiting effect on evaporation losses during the summer months in southern Europe.

The majority of GCM-based studies rely on very simple representations of the landsurface processes involved in determining soil moisture levels (Seneviratne et al., 2002). In addition, Srinivasan et al. (2000) emphasized that, while the general trend is towards drier soil conditions with projected climate change, uncertainties are large. Many GCMs currently show poor skill at reproducing the observed seasonality in rainfall at regional scales, with obvious implications for their robustness in modelling soil moisture conditions. Unrealistic summer drying is suggested by several models. Recent efforts have focused on estimating future soil moisture conditions by employing downscaled output from GCMs to run more detailed models at scales more appropriate to understanding the complex response of soil moisture conditions.

Naden and Watts (2001) found that climate change could generally lead to decreased soil water content in the UK, with very marked decreases in the south of the country, in line with simulated changes in runoff. At the landscape scale, using a single vegetation type (grassland) and a limited number of soil types, the authors found that soil type is critical in determining future changes in moisture content, with the drying effect greatest for clay soils, while sandy soils were found to be least prone to severe reductions. However, climate change scenarios within this study are based on current values of stomatal resistance and leaf area index for grassland, and do not account for species response to enhanced carbon dioxide levels.

Etchevers et al. (2002) estimated the impacts of climate change on the hydrological budget of the Rhone catchment in Europe and found strong contrasts in the hydrological response of the catchment under future climate scenarios. When considering soil water content, northern parts of the catchment remained quite wet, whereas in the southern part of the catchment enhanced drying of soils was suggested, consistent with the findings of larger scale work discussed above. In Germany, Holsten et al. (2009) examined past trends and future effects of climate change on soil moisture dynamics in the Brandenburg region with an emphasis on Special Areas of Conservation (SACs). A decreasing trend in soil water content was shown by analysing simulation results for the period 1951-2003. Regionally downscaled climate scenarios, representing the range between wetter and drier realizations, were used to evaluate the future evolution of moisture conditions and available soil water. Results indicated a continuation of present drying trends with further decreases in average soil water ranging from $-4 \%$ to $-15 \%$ up to the middle of the current century. A high level of risk for wetlands was also identified (Holsten et al., 2009).

In terms of wetlands, blanket peatlands are important and rare natural ecosystems throughout Europe, with many being located in SACs. Evans et al. (1999) used analogue conditions of the dry summer of 1995 to assess hydrological changes in peat hydrology for an area of upland blanket bog in the UK. Hulme (1997) suggested that extreme summers like that experienced in the UK in 1995 and the associated soil moisture deficits would be increasingly common by the midcentury. Reductions in summer rainfall and increases in evaporation will significantly affect the timing and quality of runoff from upland blanket peat, with the potential to trigger phases of peat erosion and alter the carbon flux from the peatland system (Evans et al., 1999). 
In perhaps the most detailed assessments to date, Jasper et al. (2006) examined future changes in summertime soil water patterns by considering climate change projections, soil and terrain characteristics, and slope and groundwater depth in the determination of future soil water evolution in the Thur river basin in Switzerland. The results of this work suggest that a warmer future climate with less precipitation in summer may significantly lower soil water content, leading to an increase in the frequency of water stress conditions. Critically, the increased level of detail incorporated into the modelling process suggests that the magnitude of future changes is closely related to land use, soil textural characteristics and slope. In relative terms, reductions in soil water were largest for soils in sloping areas with low water storage capacity, and also larger for forested areas than for cropland and grassland (Jasper et al., 2006). In volumetric terms, the largest reductions were likely for flat areas with good water supply, mostly dominated by cropland. The role of groundwater was found to be important in these areas, particularly where the rooting zone of vegetation is connected to groundwater, and capillary rise can counteract soil water depletion. This offsetting effect is lost under drying conditions in the future through the disconnection of the rooting zone with groundwater. In steeper areas, where groundwater is not a factor, the driving processes determining soil moisture changes were found to be decreased precipitation and increased evapotranspiration. A key conclusion from Jasper et al. (2006) was that the degree of soil water depletion varies with climate scenario, land use, soil texture and topographic conditions, and that in order to fully understand future changes in soil moisture due to climate change reliable precipitation scenarios are required, along with the full representation of biophysical processes that control evapotranspiration, including vertical and lateral subsurface flows.

It is clear that soil hydrological responses to climate change are multifaceted and crucially important determinants of environmental productivity and stability in many parts of Europe, as well as important determinants of the pace of future climate change itself. Two key aspects will now be dealt with in greater detail. First, desiccated soils can be expected to be particularly vulnerable to wind and water erosion and this risk has been recognized as potentially severe, especially in southern Europe (Grimm et al., 2002). Secondly, it is clear that better understanding of soil hydrology is an essential component for reducing uncertainty in modelling water resource changes and management.

\section{Soil erosion in Europe in a changing climate}

Erosion is a widespread form of soil degradation globally and poses severe limitations to sustainable agricultural land use as it reduces productivity of agricultural soils by removing the most fertile topsoil, where soils are shallow (Stone et al., 1985; Verity and Anderson, 1990; Bakker et al., 2005). Furthermore, severe erosion is commonly associated with the development of temporary or permanently eroded channels or gullies that can fragment farmland and cause deposition of sediments and accumulation of agrochemicals in water bodies (Steegen et al., 2001). The soil removed by runoff from the land during a large storm accumulates below the eroded areas, in severe cases blocking roadways or drainage channels and inundating buildings. Erosion rates are very sensitive to both climate and land use, as well as to existing conservation practices at the field or farm level.

Based on work of Valentin (1998) and Nearing et al. (2004), global change is expected to exacerbate erosion problems through changes in rainfall conditions and land use. Therefore, it is very important to be able to assess the state of soil erosion at a European level using an objective methodology that allows the assessment to be repeatable as conditions change, and also to explore the broad-scale implications of prospective global environmental changes. Erosion by running water has been identified as the most severe hazard threatening the protection of soil in Europe. The revised Common Agricultural Policy (CAP) of the European Union (EU) setaside programme is having a positive effects on the soil erosion risk (Van Rompaey et al., 2001). 
However, in order to study any risk under current and future climatic conditions, a correct assessment of erosion risk at local, national and European scales using an objective, spatially explicit methodology is important (Gobin et al., 2003). Soil erosion indicators developed from a physically based model have the potential not only to provide information on the state of soil erosion at any given time, but also to assist in understanding the links between different factors causing erosion. This not only provides a basis for estimating the overall costs attributable to erosion under present and future conditions, but, equally, helps in identifying areas that could be severely affected and potential remedial actions that might be undertaken.

\section{Modelling European soil erosion in a changing climate}

USLE has been the most widely applied model in Europe (e.g. Van der Knijff et al., 2000, 2002). This is now considered to be conceptually flawed, and other models are emerging. These are based on runoff thresholds (e.g. Kirkby et al., 2000) or the MIR (Minimum Information Requirement) approach (Brazier et al., 2001) applied to the more complex USDA WEPP model (Nearing et al., 1989). A large number of physical process-based erosion models have also been developed over recent decades, such as SWAT, WEPP, EUROSEM, KINEROS2 and LISEM. Moreover, these models have the potential to respond explicitly and rationally to changes in climate or land use, and have a potential for developing scenarios of change, and thus helping in the assessment of policy or economic options. One shortcoming is the spatial application of these relatively complex models to large areas (i.e. $>100 \mathrm{~km}^{2}$ ). The quality of the necessary input data is also frequently not sufficient.

PESERA was developed specifically to be applied to larger areas using the description of physical processes controlling sheet and rill erosion as a basis, in order to allow application using data available at the European scale. Cautiously, soil erosion and sediment transport estimated in PESERA represent only

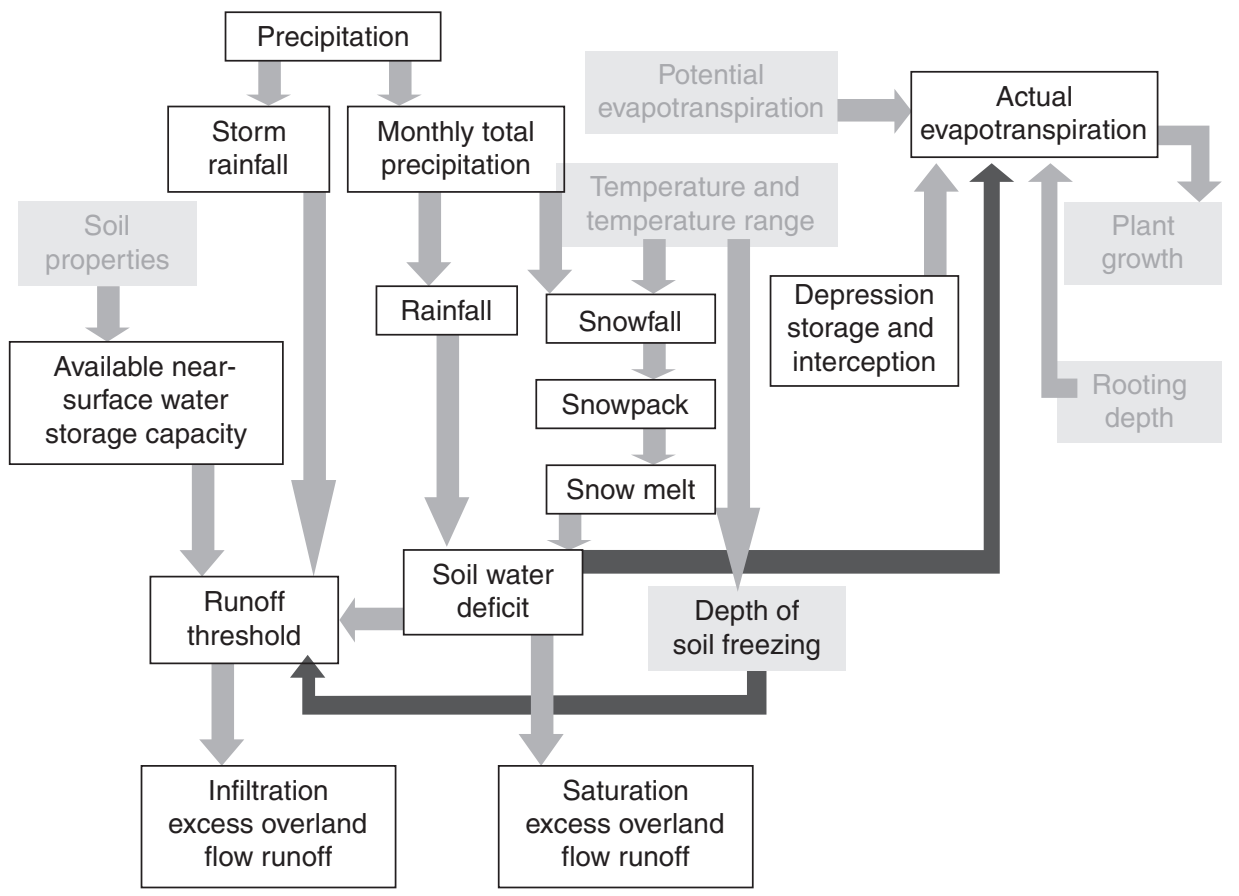

Fig. 16.1. Organization of the PESERA (Pan-European Soil Erosion Risk Assessment) model. 
the dominant sheet and rill erosion processes (Kirkby et al., 2004) important for agriculture. The PESERA model combines the effect of topography, climate and soil into a single integrated forecast of runoff and soil erosion (Fig. 16.1) that the USLE and RUSLE (Revised USLE) lack.

The PESERA model has been calibrated and validated at high and low resolutions (e.g. Gobin et al., 2003). The $1 \mathrm{~km}^{2}$ grid PESERA map (Plate 18) was validated through a visual, numerical and category comparison between measured and observed erosion rates (Gobin et al., 2003). Although these results are promising, they are not sufficient to justify the application of the model at the European scale as a prediction and scenario analysis tool. Generally, parameters have been optimized for a local situation only and with a specific temporal resolution. According to the European Environment Agency (Turner et al., 2001), there are three broad zones in Europe where soil erosion occurs: a southern (Mediterranean zone), a northern loess zone and an eastern zone. In the southern zone, severe soil erosion occurs because of intense seasonal rainfall. This is often associated with overgrazing, deforestation and a move away from traditional crops. Erosion in this zone may be long established. Many areas undergoing active tectonic uplift, such as parts of Spain, have a much higher rate of erosion than in the southern (Mediterranean) zone. The principal impact is that on-site soil productivity decreases as a result of thinning. The northern zone has moderate rates of water erosion. This mostly results from less intense rainfall falling on saturated, easily erodible soils. Impacts here are mainly off site, as the agricultural chemicals from the north's more intensive farming systems are moved into water bodies along with eroded sediments. Partially overlapping these two zones is the eastern zone, where former large state-controlled farms produced considerable erosion problems. For scenarios of alternative erosion futures, PESERA was run in conjunction with regional climate models (RCMs) and economic forecasts. The Hadley Centre's regional climate change prediction model (HadRM3) was used to drive the PESERA $1 \mathrm{~km}^{2}$ grid model. Although the interrelations between climate change and changes in soil quality are complex and not fully understood (EEA, 2000), it is obvious that changes in climate will have significant impacts on the occurrence of erosion.

In order to simplify the spatial scale, two subregions were used to provide an insight into the future erosion risks. The first covers Belgium and parts of the southern UK, northern France, Germany, the Netherlands and Luxembourg, where there are good baseline data. The second, the Mediterranean region, covers the southern part of Spain and Portugal, which is considered to be particularly prone to erosion. This is because of long dry periods followed by heavy bursts of intense rainfall, falling on steep slopes with fragile soils and low vegetation cover (Gobin et al., 2003). For the first region, the predicted soil erosion for the period 2071-2080 shows that the spread of erosion estimates is highest in late autumn and winter (October-February). The enhanced difference in erosion risk between summer and winter follows the pattern of the expected change in rainfall, with an increase in autumn and winter, and a clear decrease in the summer months. For the Mediterranean, the projected increase in winter rains in the HadRM3-A2B (A2B is one of the A2 scenarios) scenario for 2071-2080 does not lead to an increase in predicted erosion. On the contrary, erosion rates decline spectacularly. Only summer (JulyAugust) shows increases in erosion rates due to a change of erosion pattern, or more an increase in the area for which erosion (risk) is predicted. Almost all Mediterranean environments are dominated by overland flow in the summer, but in wetter environments there are substantial subsurface flow and groundwater recharge in winter (up to $75 \%$ of the total rainfall). Drier environments are dominated by overland flow almost year-round (Gobin et al., 2000). Given the spatial complexity of the model, erosion risk assessment at a local scale becomes problematic even under future climatic scenarios. Still, the overall picture at national or regional level does relate strongly to the land use. Experiments in the UK have shown that land use has a much more pronounced effect on erosion potential than climate change. However, soil vulnerability information, such as that provided by the PESARAstudy, is fundamental for determining 
appropriate land-use policies and responses to climate change (Hulme et al., 1999).

\section{Modelling the impacts of climate change on soil hydrology: addressing uncertainty}

Soil hydrological processes determine how precipitation is partitioned into infiltration, runoff, evapotranspiration and groundwater recharge. Both surface water resources and the soil moisture store react to changes in temperature and precipitation. Hydrological models can be used to model these changes in both water stores. Conceptual hydrological models use relatively simple mathematical equations to conceptualize and aggregate the complex, spatially distributed and highly interrelated water, energy and vegetation processes in a watershed. Owing to the randomness in nature and the lack of complete knowledge of the hydrological system, uncertainty is an unavoidable element in any hydrological modelling study (Beven, 2000). In climate change impact studies, conceptual hydrological models forced with regional climate change scenarios analysed from GCMs are widely used, although this approach is subject to a range of uncertainties associated with output from both the climate models and the impact models.

A wide range of GCMs developed by various climate centres is available for simulating the earth's climate. These climate models differ in the way they simplify the climate system and aggregate the process in a space and time domain. Therefore the projections of water resources are likely to vary depending upon the choice of GCMs (e.g. Prudhomme et al., 2003). Secondly, there exist large sources of uncertainty intrinsic to climate models. These can be classified as: initial conditions, boundary conditions, parameterizations and model structure. The uncertainty in climate projection arising from initial conditions is often neglected for results that are averaged over decades. The third source of uncertainty is mostly related to the computational aspects of modelling and to poor understanding of some of the important components of the climate system, and can be referred to as param- eter and structural uncertainty. Tebaldi and Knutti (2007) argued that the quantification of all aspects of model uncertainty requires multi-model ensembles. Giorgi and Mearns (2002) introduced the Reliability Ensemble Averaging (REA) method for calculating the uncertainty range from ensembles of different atmosphere-ocean general circulation models. Similarly, Tebaldi et al. (2005) extended the REA method and proposed a Bayesian statistical model that combines information from a multimodal ensemble of atmosphere-ocean GCMs and observations to determine probability distributions of future temperature change on a regional scale. These assessments have been greatly facilitated by the Coupled Model Inter-comparison Project phase 3 (CMIP3) climate model output archive. Several studies used the output archived in Coupled Model inter-comparison projects to account for uncertainty in the GCM, and several others used the output from perturbed physics ensembles to evaluate the uncertainties arising from GCM model formulation (e.g. Murphy et al., 2007). Furthermore, while output from GCMs reproduces the global- and continental-scale climate fairly well, GCMs are inadequate in impact studies owing to the differences in the spatial scales of GCMs and those needed for impact studies (Wilby and Wigley, 1997). This limitation has been widely addressed through downscaling. Methods of downscaling differ in the way that they reproduce various statistical characteristics of observed data in its downscaled results (Wilby and Wigley, 1997; Khan and Iqbal, 2009). New and Hulme (2000) presented an approach to quantifying uncertainties associated with the estimation of future greenhouse gas emissions, the climate sensitivity, and limitations and unpredictability in GCMs.

As with GCMs, uncertainty occurs in hydrological models from a variety of sources. These include: data uncertainty, parameter uncertainty, model structural uncertainty and state uncertainty. An extensive review of the causes of uncertainty in hydrological models and of various methods for assessing the uncertainty can be found in Melching (1995). Among various methods for assessing the uncertainty of hydrological models, the Generalized Likelihood Uncertainty 
Estimation (GLUE) method has been extensively used (e.g. Freer et al., 1996). Though the uncertainties that result from dependence on a single conceptual-mathematical model are typically much larger than those introduced through an inadequate choice of model parameter values, most hydrological uncertainty analyses ignore the former and focus exclusively on the latter. A review of the range of strategies for assessing structural uncertainties in environmental modelling are available in Refsgaard et al. (2006). These strategies can be broadly grouped into two, depending upon whether or not target data are available. In the application of hydrological models in climate change impact assessment, the structure of the hydrological model cannot be assessed directly using observation. Therefore the main strategy to account for modelling uncertainties is to do the extrapolation with multiple conceptual models. This approach has been used by Butts et al. (2002).

Though many impact studies have introduced methods to account for uncertainties associated with the estimation of future greenhouse gas emissions, climate sensitivity, and limitations and unpredictability in GCMs (e.g. New and Hulme, 2000), very few have looked at the uncertainties related to hydrological models. The use of hydrological response to the climatic scenarios resulting from the use of different hydrological models with different climate models will also allow more knowledge concerning the vital role of soil hydrological processes to be obtained.

\section{Accounting for modelling uncertainties: a case study using basins located in Ireland}

As already outlined in the Material and Methods section, the impact of climate change on water resources at the catchment scale was investigated using four Irish catchments: Blackwater at Ballyduff $\left(2302 \mathrm{~km}^{2}\right)$, Suck at Bellagill $\left(1219 \mathrm{~km}^{2}\right)$, Moy at Rahans $\left(1803 \mathrm{~km}^{2}\right)$ and Boyne at Slane $\left(2452 \mathrm{~km}^{2}\right)$. These four catchments were selected so that they represent the diverse hydrological responses of different catchments located throughout Ireland. Four hydrological models (HyMOD,
NAM, TOPMODEL and Tank) were used with six sets of statistically downscaled climate scenarios (temperature and precipitation) derived from three GCMs (HadCM3, CCCMA and CSIRO-Mk2) and two emission scenarios (A2 and B2) (Fealy and Sweeney, 2007).

In order to examine the role of model uncertainty (parameter and structural uncertainty) in climate change impact studies and include a full consideration of impact model uncertainty, the GLUE method was used. The sets of behavioural predictions from different models were ranked and likelihood weighted to characterize the parameter as well as structural uncertainty propagated through hydrological models. The informal likelihood measure assumed is the Nash-Sutcliffe efficiency measure, widely used as a performance measure in hydrological modelling. To construct the total uncertainty, envelope inputs from the six climate change scenarios were used together with four hydrological models, each with a number of plausible model parameter sets. Predictions from the three GCMs were weighted based on the ability of the individual GCM to reproduce the properties of the observations.

The results show that the average width of the prediction interval arising from uncertainties associated with parameterization of hydrological modelling is nearly $40 \%$ of the average flow, increasing to nearly $70 \%$ of the average flow when different model structures are included. This indicates that the uncertainty arising from the uncertainty in the structure of hydrological model can have significant impact on the reliability of the future projection of water resources at catchment scale. Plate 19 illustrates the hydrological response (streamflow) simulated by the behavioural set of model parameters of four different hydrological models of the River Boyne catchment to HadCM3 forced with the A2 scenario. Plate 20 shows a seasonal prediction interval for the control (observed) period (1970-1990) and the future period (2020-2079). These were constructed based on the behavioural predictions obtained from the entire suite of models, which were ranked and likelihood weighted to produce upper $95 \%$, lower $5 \%$ and median $50 \%$ quantiles of the simulation results. The overall uncertainty envelope increased to 
nearly $40 \%$ of the average streamflow for the three periods simulated, namely the 2020s, 2050s and 2070s. Similarly, Plate 21 shows the observed seasonal streamflow for the period 1970-1990 and the median seasonal streamflow estimated for the future period. There is a progressive increase of winter discharge when moving from the 2020s to the 2070s, and a progressive decrease in summer discharge from the 2020s to the 2070s. The case study shows that the role of hydrological model uncertainty is remarkably high and therefore it should be routinely considered in impact studies.

\section{Summary and Conclusions}

Detailed understanding of soil hydrology is needed for future protection of soils in Europe. For much of the continent, the EU Water Framework Directive will indirectly act as a vehicle to facilitate this by providing a regulatory influence on land use, together with an 'as-yet-to-be agreed' Soils Directive. However, it is clear that soil hydrological responses to climate change are multifaceted and crucially important determinants of environmental productivity and stability in many parts of Europe, as well as important determinants of the pace of future climate change itself. Therefore, they should be considered explicitly in long-term integrated river basin management. Changes in soil moisture due to climate change are likely to show a high degree of spatial variability and significant levels of uncertainty. To date, studies have indicated an increase in the moisture content of soils in winter and a substantial decrease in summer, particularly in southern Europe. Furthermore, the soil erosion modelled at national or regional levels relates strongly to the land use, indicating that erosion problems are also expected to be exacerbated through changes in land use.

Improving our understanding of how climate change could influence soil hydrology has been mostly hindered by scores of uncertainties. Many impact studies have introduced methods to account for uncertainties associated with the estimation of future greenhouse gas emissions, climate sensitivity, and limitations and unpredictability in GCMs; very few have looked at the uncertainties related to hydrological models. Hydrological modelling exhibits considerable uncertainties in both parameterization and structural characteristics. This has been addressed here by using a multi-model approach that combines multiple emission scenarios, GCMs and conceptual rainfall runoff models, and demonstrated through the modelling of four Irish catchments. The results indicate that the uncertainty arising from the uncertainty in the structure of hydrological models can have a significant impact on the reliability of the future projection of water resources at catchment scale.

Roughly $90 \%$ of the land in Ireland is under one or other varying forms of land use for agricultural production. The impacts of climate change on soil hydrological processes have a direct relevance in terms of biomass production and nutrient management as the agro-ecosystems are predominantly rainfed. The preparedness of agriculture to adopt irrigation regimes is entirely dependent on the water balance of the respective river basins. Hence, projecting the demands of water availability through hydrological modelling is a valuable tool for sustainable water management. Changing land-use patterns in Ireland will reflect water availability rather than temperatures, as this seems to be the most limiting factor during the crop growth period.

It may be concluded that climate change will have significant impacts on soil hydrological processes throughout Europe. While temperature increases will decrease carbon storage and reduce soil organic matter, with consequent implications for soil moisture storage, it is likely to be the projected precipitation changes that will have most impact. Soil moisture responses will be crucially important for regulating surface and groundwater resources, and ultimately for influencing agricultural potential. Soil erosion is likely to become a problem in southern Europe as a result of intense convective downpours in summer occurring after prolonged dry periods. 
The majority of GCM-based studies rely on very simple representations of the landsurface processes involved in determining soil moisture levels. Many GCMs currently show poor skill at reproducing the observed seasonality in rainfall at regional scales, with obvious implications for their robustness in modelling soil moisture conditions. Future efforts are required to focus on estimating future soil moisture conditions by employing downscaled output from GCMs to run more detailed models at scales more appropriate to understanding the complex response of soil moisture conditions. Furthermore, hydrological modelling still exhibits considerable uncertainties in both parameterization and structural characteristics. These are further compounded by intrinsic uncertainties in the driving climate models, and this requires recognition in impact studies as well as further research designed to minimize them.

\section{References}

Alcamo, J., Floerke, M. and Maerker, M. (2007) Future long-term changes in global water resources driven by socio-economic and climatic changes. Hydrological Sciences 52, 247-275.

Alexander, L.V., Zhang, X., Peterson, T.C., Caesar, J., Gleason, B., Klein Tank, A.M.G., Haylock, M., Collins, D., Trewin, B., Rahimzadeh, F., Tagipour, A., Rupa Kumar, K., Revadekar, J., Griffiths, G., Vincent, L., Stephenson, D.B., Burn, J., Aguilar, E., Brunet, M., Taylor, M., New, M., Zhai, P., Rusticucci, M. and Vazquez-Aguirre, J.L. (2006) Global observed changes in daily climate extremes of temperature and precipitation. Journal of Geophysical Research 111, D05109, doi:10.1029/2005JD006290.

Bakker, M.M., Govers, G., Ewert, F., Rounsevell, M. and Jones, R. (2005) Variability in regional wheat yields as a function of climate, soil and economic variables: assessing the risk of confounding. Agriculture, Ecosystems and Environment 110, 195-209.

Beven, K., Lamb, R., Quinn, P., Romanowicz, R. and Freer, J. (1995) TOPMODEL. In: Singh, V.P. (ed.) Computer Models of Watershed Hydrology. Water Resources Publications, Littleton, Colorado, pp. 627-668.

Beven, K.J. (2000) Rainfall-runoff Modelling - The Primer. John Wiley, Chichester, UK.

Brabson, B.B., Lister, D.H., Jones, P.D. and Palutikof, J.P. (2005) Soil moisture and predictive spells of extreme temperatures in Britain. Journal of Geophysical Research: Atmospheres 110, D05104, doi:10.1029/2004JD005156.

Brazier, R.E., Rowan, J.S., Quinn, P. and Anthony, S. (2001) Towards an MIR (Minimum Information Requirement) approach to modelling on-site soil loss at the national scale. Catena 42, 59-79.

Butts, M.B., Hoest-Madsen, J. and Refsgaard, J.C. (2002) Hydrologic forecasting. In: Meyers, R.A. (ed.) Encyclopaedia of Physical Science and Technology. Academic Press, Oxford, UK, pp. 547-566.

Daly, E. and Porporato, A. (2005) A review of soil moisture dynamics: from rainfall infiltration to ecosystem response. Environmental Engineering Science 22, 9-24.

De Roo, A.P.J., Wesseling, C.G. and Ritsema, C.J. (1996) LISEM: a single-event physically based hydrological and soil erosion model for drainage basins. I. Theory, input and output. Hydrological Processes 10, 1107-1117.

EEA (2000) Down to Earth: Soil Degradation and Sustainable Development in Europe. A Challenge for the 21st Century. Environmental Issue Series No. 16, European Environment Agency (EEA), Copenhagen.

Etchevers, P., Golaz, C., Habets, F. and Noilhan, J. (2002) Impact of climate change on the Rhone river catchment hydrology. Journal of Geophysical Research: Atmospheres 107 (D16), 4293, doi:10.1029/2001JD000490.

Evans, M.G., Burt, T.P., Holden, J. and Adamson, J.K. (1999) Runoff generation and water table fluctuations in blanket peat: evidence from UK data spanning the dry summer of 1995. Journal of Hydrology 221, 141-160.

Favis-Mortlock, D.T. and Boardman, J. (1995) Nonlinear responses of soil erosion to climate change: a modelling study on the UK South Downs. Catena 25, 365-387.

Fealy, R. and Sweeney, J. (2007) Statistical downscaling of precipitation for a selection of sites in Ireland employing a generalised linear modelling approach. International Journal of Climatology 27, 2083-2094. 
Fischer, E.M., Seneviratne, S.I., Vidale, P.L., Lüthi, D. and Schär, C. (2007) Soil moisture-atmosphere interactions during the 2003 European summer heat wave. Journal of Climate 20, 5081-5099.

Flanagan, D.C. and Livingston, S.J. (eds) (1995) Water Erosion Prediction Project (WEPP) Version 95.7: User Summary. NSERL Report No. 11, National Soil Erosion Research Laboratory, USDA Agricultural Research Service, West Lafayette, Indiana.

Frederick, K.D. and Major, D.C. (1997) Climate change and water resources. Climatic Change 37, 7-23.

Freer, J., Beven, K.J. and Ambroise, B. (1996) Bayesian uncertainty in runoff prediction and the value of data: an application of the GLUE approach. Water Resources Research 32, 2163-2173.

Gerten, D., Schaphoff, S. and Lucht, W. (2007) Potential future changes in water limitations of the terrestrial biosphere. Climatic Change 80, 277-299.

Giorgi, F. and Mearns, L.O. (2002) Calculation of average, uncertainty range, and reliability of regional climate changes from AOGCM simulations via the "reliability ensemble averaging" (REA) method. Journal of Climate 15, 1141-1158.

Giorgi, F., Bi, X. and Pal, J. (2004) Mean interannual and trends in a regional climate change experiment over Europe. II: Climate Change scenarios (2071-2100). Climate Dynamics 23, 839-858.

Gobin, A., Cerdan, O. and Govers, G. (eds) (2003) Pan European Soil Erosion Risk Assessment: Third Annual Report. EU 5th Framework Programme. Project No. QLK5-CT-1999-01323. Available at: http://eusoils.jrc.it (accessed 16 March 2010).

Good, P., Barring, L., Giannakopoulos, C., Holt, T. and Palutikof, J.P. (2006) Non-linear regional relationships between climate extremes and annual mean temperatures in model projections for 1961-2099 over Europe. Climate Research 13, 19-34.

Gregory, J.M., Mitchell, J.F.B. and Brady, A.J. (1997) Summer drought in northern midlatitudes in a timedependent $\mathrm{CO}_{2}$ climate experiment. Journal of Climate 10, 662-686.

Grimm, M., Jones, R.J.A. and Montanarella, L. (2002) Soil Erosion Risk in Europe. EUR 19939 EN, European Soil Bureau, Institute for Environment and Sustainability, European Commission Joint Research Centre, Ispra, Italy,.

Holsten, A., Vetter, T., Vohland, K. and Krysanova, V. (2009) Impact of climate change on soil moisture dynamics in Brandenburg with a focus on nature conservation areas. Ecological Modelling 220, 2076-2087.

Hulme, M. (1997) The climate in the UK from November 1994 to October 1995. Weather 52, 242-257.

Hulme, M., Barrow, E.M., Arnell, N.W., Harrison, P.A., Johns, T.C. and Downing, T.E. (1999) Relative impacts of human-induced climate change and natural climate variability. Nature 397, 688-691.

Jasper, K., Calanca, P. and Fuhrer, J. (2006) Changes in summertime soil water patterns in complex terrain due to climatic change. Journal of Hydrology 27, 550-563.

Johnson, H., Kovats, R.S., McGregor, G., Stedman, J., Gibbs, M. and Walton, H. (2005) The impact of the 2003 heatwave on daily mortality in England and Wales and the use of rapid weekly mortality estimates. Euro Surveillance 10, 168-171.

Khan, M.J. and Iqbal, M.T. (2009) Analysis of a small wind-hydrogen stand-alone hybrid energy system. Applied Energy 86, 2429-2442.

Kirkby, M.J., Le Bissonais, Y., Coulthard, T.J., Daroussin, J. and McMahon, M.D. (2000) The development of land quality indicators for soil degradation by water erosion. Agriculture, Ecosystems and Environment 81, 125-136.

Kirkby, M.J., Jones, R.J.A., Irvine, B., Gobin, A, Govers, G., Cerdan, O., Van Rompaey, A.J.J., Le Bissonnais, Y., Daroussin, J., King, D., Montanarella, L., Grimm, M., Vieillefont, V., Puigdefabregas, J., Boer, M., Kosmas, C., Yassoglou, N., Tsara, M., Mantel, S., Van Lynden, G.J. and Huting, J. (2004) Pan-European Soil Erosion Risk Assessment: The PESERA Map, Version 1 October 2003. Explanation of Special Publication Ispra 2004 No. 73 (S.P.I.04.73). European Soil Bureau Research Report No.16, EUR 21176 and map in ISO B1 format, European Commission Joint Research Centre, Ispra/Institute for Environment and Sustainability. Available from: Office for Official Publications of the European Communities, Luxembourg, and at: http://eusoils.jrc.ec.europa.eu/esdb_archive/pesera/ ThePeseraMapBkLet52.pdf (accessed 4 March 2011).

Kirschbaum, M.U.F. (1995) The temperature dependence of soil organic matter decomposition and the effect of global warming on soil organic carbon storage. Soil Biology and Biochemistry 27, 753-760.

Kosmas, C., Danalatos, N.G., Cammeraat, L.H., Chabart, M., Diamantopoulos, J., Farand, R., Gutierrez, L., Jacob, A., Marques, H., Martinez-Fernandez, J., Mizara, A., Moustakas, N., Nicolau, J.M., Oliveros, C., Pinna, G., Puddu, R., Puigdefabregas, J., Roxo, M., Simao, A., Stamou, G., Tomasi, N., Usai, D. and Vacca, A. (1997) The effect of land use on runoff and soil erosion rates under Mediterranean conditions. Catena 29, 45-59. 
Madsen, H. (2000) Automatic calibration of a conceptual rainfall-runoff model using multiple objectives. Journal of Hydrology, 235, 276-288.

Melching, C.S. (1995) Reliability estimation. In: Singh, V. P. (ed.) Computer Models of Watershed Hydrology. Water Resources Publications, Littleton, Colorado, pp. 69-118.

Morgan, R.P.C., Quinton, J.N. and Smith, R.E. (1998) The European Soil Erosion Model (EUROSEM): a dynamic approach for predicting sediment transport from fields and small catchments. Earth Surface Processes and Landforms 23, 527-544.

Murphy, J.M., Booth, B.B.B., Collins, M., Harris, G.R., Sexton, D.M.H. and Webb, M.J. (2007) A methodology for probabilistic predictions of regional climate change from perturbed physics ensembles. Philosophical Transactions of the Royal Society A 365, 1993-2028.

Naden, P.S. and Watts, C.D. (2001) Estimating climate-induced change in soil moisture at the landscape scale: an application to five areas of ecological interest in the UK. Climatic Change 49, 411-440.

Nearing, M.A., Foster, G.R., Lane, L.J. and Finkner, S.C. (1989) A process-based soil-erosion model for USDA-water erosion prediction project technology. Transactions of the ASAE 32, 1587-1593.

Nearing, M.A., Pruski, F.F. and O'Neal, M.R. (2004) Expected climate change impacts on soil erosion rates: a review. Journal of Soil and Water Conservation 59, 43-50.

Neitsch, S.L., Arnold, J.G., Kiniry, J.R., Williams, J.R. and King, K.W. (2002) Soil and Water Assessment Tool Theoretical Documentation, Version 2000. GSWRL Report 02-01, Grassland, Soil and Water Research Laboratory, USDA ARS (Agricultural Research Service)/BRC Report 2-05, Blackland Research and Extension Center, Texas Agricultural Experiment Station, Temple, Texas/TWRI Report TR-191, Texas Water Resources Institute, College Station, Texas.. Available at: http://swatmodel. tamu.edu/media/1290/swat2000theory.pdf (accessed 17 February 2011).

New, M. and Hulme, M. (2000) Representing uncertainty in climate change scenarios: a Monte-Carlo approach. Integrated Assessment 1, 203-213.

Nicholson, S. (2000) Land surface processes and Sahel climate. Reviews of Geophysics 38, 117-139.

Porporato, A., Laio, F., Ridolfi, L. and Rodriguez-lurbe, I. (2001) Plants in water-controlled ecosystems: active role in hydrologic processes and response to water stress. III. Vegetation water stress. Advances in Water Resources 24, 725-744.

Prudhomme, C., Jakob, D. and Svensson, C. (2003) Uncertainty and climate change impact on the flood regime of small UK catchments. Journal of Hydrology 277, 1-23.

Pruski, F.F. and Nearing, M.A. (2002) Climate-induced changes in erosion during the 21 st century for eight U.S. locations. Water Resources Research 38, 1298.

Räisänen, J., Hansson, U., Ullerstig, A., Döscher, R., Graham, L.P., Jones, C., Meier, M., Samuelsson, P. and Willén, U. (2004) European climate in the late 21st century: regional simulations with two driving global models and two forcing scenarios. Climate Dynamics 22, 13-31.

Refsgaard, J.C., Van der Sluijs, J.P., Brown, J. and Van der Keur, P. (2006) A framework for dealing with uncertainty due to model structure error. Advances in Water Resources 29, 1586-1597.

Seneviratne, S.I., Pal, J.S., Eltahir, E.A.B. and Schar, C. (2002) Summer dryness in a warmer climate: a process study with a regional climate model. Climate Dynamics 20, 69-85.

Smith, R.E., Goodrich, D.C. and Quinton, J.N. (1995) Dynamic, distributed simulation of watershed erosion: the KINEROS2 and EUROSEM models. Journal of Soil and Water Conservation 50, 517-520.

Srinivasan, G., Robock, A., Entin, J.K., Luo, L., Vinnikov, K.Y. and Viterbo, P. (2000) Soil moisture simulations in revised AMIP models. Journal of Geophysical Research 105, 26635-26644.

Steegen, A., Govers, G., Takken, I., Nachtergaele, J., Poesen, J. and Merckx, R. (2001) Factors controlling sediment and phosphorus export from two Belgian agricultural catchments. Journal of Environmental Quality 30, 1249-1258.

Stone, J.R., Gilliam, J.W., Cassel, D.K., Daniels, R.B., Nelson, L.A. and Kleiss, H.J. (1985) Effect of erosion and landscape position on the productivity of Piedmont soils. Soil Science Society of America Journal 49, 987-991.

Sugawara, M. (1995) Tank model. In: Singh, V.P. (ed.) Computer Models of Watershed Hydrology. Water Resources Publications, Littleton, Colorado, pp. 165-214.

Tebaldi, C. and Knutti, R. (2007) The use of the multimodel ensemble in probabilistic climate projections. Philosophical Transactions of the Royal Society A 365, 2053-2075.

Tebaldi, C., Smith, R.L., Nychka, D. and Mearns, L.O. (2005) Quantifying uncertainty in projections of regional climate change: a Bayesian approach to the analysis of multimodel ensembles. Journal of Climate 18, 1524-1540. 
Ting, M., Kushnir, Y., Seager, R. and Li, C. (2009) Forced and internal 20th century SST trends in the North Atlantic. Journal of Climate 22, 1469-1481.

Turner, S., Lyons, H. and Favis-Mortlock, D. (2001) Analysis and mapping of soil problem areas (hot spots) in Europe. Final Report to the European Environment Agency. In: Where Are the 'Hot Spots' of Soil Degradation in Europe? CD-ROM distributed to EIONET for review. European Environment Agency, Copenhagen.

Valentin, C. (1998) Towards an improved predictive capability for soil erosion under global change. In: Boardman, J. and Favis-Mortlock, D. (eds) Modelling Soil Erosion by Water. Springer-Verlag, Berlin, pp., 7-17.

Van der Knijff, J., Jones, R.J.A. and Montanarella, L. (2000) Soil Erosion Risk Assessment in Europe. Office for Official Publications of the European Communities, Luxembourg.

Van der Knijff, J., Jones, R.J.A. and Montanarella, L. (2002) Soil erosion risk assessment in Italy. In: Rubio, J.L., Morgan, R.P.C., Asins, S. and Andreu, V. (eds) Proceedings of the Third International Congress: Man and Soil at the Third Millennium. Geoforma Ediciones, Logrono, Spain, pp. 1903-1913.

Van Rompaey, A., Govers, G., Van Hecke, E. and Jacobs, K. (2001) The impacts of land use policy on the soil erosion risk: a case study in the Belgian Loam Belt. Agriculture, Ecosystems and Environment 83, 83-94.

Verity, G.E. and Anderson, D.W. (1990) Soil erosion effects on soil quality and yield. Canadian Journal of Soil Science 70, 471-484.

Wagener, T., Boyle, D.P., Lees, M.J., Wheater, H.S., Gupta, H.V. and Sorooshian, S. (2001) A framework for development and application of hydrological models. Hydrological and Earth Sciences 5, 13-26.

Ward, S., Connolly, J., Walsh, J., Dahlman, L. and Holden, N.M. (2007) Climate Change: Modelling Carbon Fluxes from Irish Peatlands: Towards the Development of a National Carbon Fluxes Inventory for Irish Peatland. Environmental Research, Technological Development and Innovation (ERTDI) Programme (2000-2006), Synthesis Report. Environmental Research Report 53, Environmental Protection Agency (EPA), Johnstown, Ireland.

Wilby, R.L. and Wigley, T.M.L. (1997) Downscaling general circulation model output: a review of methods and limitations. Progress in Physical Geography 21, 530-548. 